\title{
Hydrocephalus and cysticercosis
}

\author{
Somsri Wiwanitkit • Viroj Wiwanitkit
}

Received: 20 September 2011 / Accepted: 10 November 2011 /Published online: 24 November 2011

(C) Springer-Verlag 2011

\section{Dear Editor:}

The recent publication on hydrocephalus and cysticercosis is very interesting [1]. We would like to share some ideas on hydrocephalus and cysticercosis. Indeed, this condition is a deadly condition that needs proper management. Similar to Matushita et al.'s note, Sotelo proposed that "The use of one or various therapeutic measures largely depends on the peculiar combination of number, location, and biological stage of lesions as well as the degree of inflammatory response to the parasites [2]." However, to derive success in treatment, awareness and early diagnosis can lead to prompt effective treatment. There are some new alternative techniques for diagnosis to be mentioned. A good example is "Full moon" endoscopic sign which can help diagnose the case and further minimally invasive therapeutic approach can be done [3].

\section{References}

1. Matushita H, Pinto FC, Cardeal DD, Teixeira MJ (2011) Hydrocephalus in neurocysticercosis. Childs Nerv Syst 27(10):17091721

2. Sotelo J (2011) Clinical manifestations, diagnosis, and treatment of neurocysticercosis. Curr Neurol Neurosci Rep 11(6):529-535

3. Ramos-Zúñiga R, de La Cruz-Ramírez J, Casillas-Espinosa PM, Sánchez-Prieto JA, López-Hernández MD (2011) "Full moon" endoscopic sign in intraventricular neurocysticercosis. Minim Invasive Neurosurg 54(2):90-94

S. Wiwanitkit $(\bowtie) \cdot$ V. Wiwanitkit

Wiwanitkit House,

Bangkhae,

Bangkok, Thailand 10160

e-mail: somsriwiwan@hotmail.com 